University of Nebraska - Lincoln

DigitalCommons@University of Nebraska - Lincoln

March 1983

\title{
Genetic and Environmental Determinants of Wing Polymorphism in the Waterstrider Limnoporus canaliculatus
}

Anthony J. Zera

University of Nebraska - Lincoln, azera1@unl.edu

David J. Innes

State University of New York, Stony Brook

Margaret E. Saks

State University of New York, Stony Brook

Follow this and additional works at: https://digitalcommons.unl.edu/bioscizera

Part of the Microbiology Commons

Zera, Anthony J.; Innes, David J.; and Saks, Margaret E., "Genetic and Environmental Determinants of Wing Polymorphism in the Waterstrider Limnoporus canaliculatus" (1983). Anthony Zera Publications. 21.

https://digitalcommons.unl.edu/bioscizera/21

This Article is brought to you for free and open access by the Papers in the Biological Sciences at DigitalCommons@University of Nebraska - Lincoln. It has been accepted for inclusion in Anthony Zera Publications by an authorized administrator of DigitalCommons@University of Nebraska - Lincoln. 


\title{
Genetic and Environmental Determinants of Wing Polymorphism in the Waterstrider Limnoporus canaliculatus
}

\author{
Anthony J. Zera, David J. Innes, and Margaret E. Saks \\ Department of Ecology and Evolution, State University of New York, Stony Brook, New York 11794
}

Submitted July 1981; revised August 1982.

Wing polymorphism commonly occurs in many insects, especially species of Orthoptera, Coleoptera, Homoptera, and Hemiptera (Harrison, 1980). The polymorphism consists of discrete differences in wing length with morphs exhibiting fully developed, reduced, or totally absent wings. In addition to differences in wing length, morphs often differ in a number of other characteristics such as degree of flight muscle development, duration of nymphal development, time to first reproduction, fertility and diapause (Anderson, 1973; Vepsäläinen, 1978; Harrison, 1980).

Wing polymorphism is an attractive system for investigating the evolution of dispersal in natural populations (Vepsäläinen, 1978; Denno and Grissell, 1979; Harrison, 1980). A key step in such studies is the identification of the environmental and genetic components of morph determination. Numerous studies of insects from several different orders have clearly demonstrated that environmental variables such as photoperiod, temperature and density may strongly influence the development of an individual into a particular morph (see references in Harrison, 1980). However, the genetic component of morph determination is poorly understood.

In a number of studies, attempts have been made to identify the genetic basis of determination in species of waterstriders (Gerridae: Hemiptera), and the results used to formulate models of the evolution of winglessness. Poisson (1924) claimed that results of crossing experiments with Gerris lacustris were consistent with a single-locus two-allele model, with the allele for short wings dominant to the allele for long wings. Ekblom $(1941,1949)$, on the other hand, concluded that wing polymorphism was under polygenic control in G. asper. Results of subsequent genetic studies in G. lacustris and G. lateralis by Vepsäläinen (1974a) and G. lacustris and G. asper by Guthrie (1959) were purported to corroborate Poisson's single locus model in a modified form. Although recognizing that morph determination is influenced by environmental factors such as photoperiod and temperature, both Guthrie (1959) and Vepsäläinen (1974a) reported that under certain environmental conditions results of their crossing experiments were consistent with a single locus or supergene (Vepsäläinen, 1974a) model. However, results of these studies are open to question. Vepsäläinen (1974a) used field-collected females in his study. Since these females may have mated in the field with males of a morph type different from those used in the laboratory crosses, his data are equivocal. Similarly, Guthrie (1959) did not report taking any precautions to insure that virgin females were used in laboratory crosses. Studies by Poisson (1924), Ekblom (1941, 1949) and Guthrie (1959) did not adequately control environmental variables such as photoperiod and temperature which are now known or are strongly suspected to influence morph determination (Vepsäläinen, 1974a). In addition, in all studies which claimed to demonstrate that morph type was inherited as a monogenic trait, progeny ratios of crosses were, in many cases, inconsistent with this model. Consequently, there are no reliable genetic data on morph determination for any gerrid species, and models of the evolution of winglessness based on assumptions of a particular mode of inheritance derived from these studies are also questionable (see Discussion).

In this study we focused on the genetic in- 
TABLE 1. Frequency of the long-winged (MAC) morph in populations of Limnoporus canaliculatus sampled in 1978. Populations are as follows: $P T=$ Petersham, Mass; $P R=$ Pink Ravine, Stows, $C T$.; NI=Niantic, CT.; NISS = Nissequogue River State Park, Long Island, N.Y. Numbers in parentheses refer to sample sizes.

\begin{tabular}{lcccc}
\hline \hline \multirow{2}{*}{ Date sampled } & \multicolumn{3}{c}{ Locality } & \multicolumn{1}{c}{ NISS } \\
\cline { 2 - 5 } & \multicolumn{1}{c}{ PT } & PR & \multicolumn{1}{c}{ N } & $0.00(63)$ \\
\hline $7 / 20-7 / 31$ & $0.00(52)$ & $0.03(39)$ & $0.00(50)$ & $0.02(58)$ \\
$8 / 2-8 / 8$ & $0.10(110)$ & $0.03(147)$ & $0.15(87)$ & $0.04(251)$ \\
$9 / 30-10 / 2$ & $0.49(222)$ & $0.67(218)$ & $0.91(241)$ & \\
\hline
\end{tabular}

fluences of morph determination in the wingpolymorphic waterstrider, Limnoporus canaliculatus. We wished to determine if the inheritance of morph type could be explained by the single locus (or supergene) model proposed by most workers for other gerrid species, or whether a more complex genetic explanation was required. We used "split brood" experiments to determine if the mode of inheritance was different under different photoperiods as well as to assess the influence of photoperiod on morph determination.

\section{MATERIALS AND METHODS}

\section{Species Studied}

Limnoporus canaliculatus is a semi-aquatic hemipteran which occurs on the surface of ponds and streams. The distribution and life cycle of this species has previously been reported (Calabrese, 1979; Zera, 1981a). Populations of L. canaliculatus consist of various proportions of fully winged, wingless, and (very rarely) short-winged individuals. Morph frequencies exhibit considerable temporal and spatial variation. For example, populations in New York, Massachusetts, and Connecticut sampled in July, 1978 consisted almost exclusively of wingless individuals while the same populations sampled in September and October were wing-polymorphic (Table 1).

\section{Crossing Experiments}

The breeding scheme used in crossing experiments is given in Figure 1. Adults were collected at the Nissequogue River State Park, Smithtown, New York (frequency of the long- winged morph in October, $1978=.04, \mathrm{~N}=$ 251; Table 1). Adults were pair-crossed in the laboratory, and 1-2 generations reared at 24.5 $\pm 1.5{ }^{\circ} \mathrm{C}, 16$ light: 8 dark, constant photoperiod, prior to the start of crossing experiments. This was done 1) to obtain virgin females, 2) to eliminate potential maternal effects and 3) to obtain a parental generation which had been reared under known conditions for crossing experiments. Mating pairs and developing eggs were maintained at $24.5 \pm 1.5^{\circ} \mathrm{C}$ and 16L:8D constant photoperiod. $24.5{ }^{\circ} \mathrm{C}$ was chosen as the experimental temperature since L. canaliculatus had previously been shown to breed and develop in a manageable period of time (approximately 35-40 days) at this temperature (Zera, 1981b). Adults were stored at $13{ }^{\circ} \mathrm{C}$, continuous light until needed to make appropriate crosses. Females were used in crossing experiments only if they had emerged in containers without adult males.

For pair crosses, a male and female L. canaliculatus were placed in a 1 liter plastic beaker half filled with distilled water containing a small piece of styrofoam as a substrate for egg laying. Each day adults were fed freshly killed houseflies or Drosophila melanogaster. Approximately every third day, the styrofoam pieces containing attached eggs were removed from the beakers and placed in separate containers filled with distilled water. Each day newly hatched nymphs were counted and placed in appropriate containers. Nymphs were fed freshly killed $D$. melanogaster until 3rd instar, and houseflies or D. melanogaster thereafter. Both the amount and type of food fed to developing nymphs were kept constant. Except 


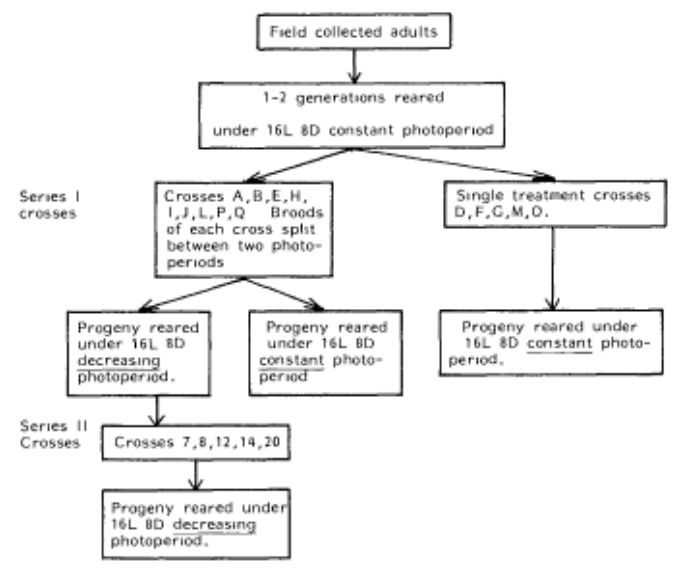

Figure 1. Experimental design used in crossing experiments of Limnoporus canaliculatus. All mating pairs were maintained under 16L:8D constant photoperiod. See Materials and Methods for details.

for the first three days of development, density of progeny was kept between 3-7 individuals per $100 \mathrm{~cm}^{2}$. We considered it unlikely that differences in density for a short period of time early in development would have an effect on morph determination. No association between density and morph frequency was observed in samples of over 30 natural populations of $L$. canaliculatus suggesting that density does not influence morph determination (Zera, unpubl.). Jarvinen and Vepsäläinen (1976) argue that density per se is unlikely to influence morph determination in gerrids during any stage of development.

Crosses were set up in all possible morph combinations in order to determine the contribution of genetic differences to variation in morph ratios. Progeny of crosses were raised under two different photoperiod regimes: 1) 16L:8D, constant, or 2) 16L:8D light phase decreasing 15 minutes every 48 hours. The decreasing photoperiod treatment, of necessity, differed from the $16 \mathrm{~L}$ constant photoperiod in having both a decremental change in daylength as well as a shorter absolute daylength. Any difference in morph frequencies between these two treatments could be due to either or both of these factors. Thus, the $16 \mathrm{~L}$ constant and $16 \mathrm{~L}$ decreasing treatments will henceforth be re- ferred to as long-constant and short-decreasing, respectively. A decreasing photoperiod treatment was included since both change and direction of change of day-length are reported to influence morph determination in at least one gerrid species (Vepsäläinen, 1974a). As mentioned previously, winged morphs are produced in the fall in L. canaliculatus when absolute daylength is short and decreasing.

A "split brood" design, that is, rearing portions of progeny of a particular cross under different treatments, was used to assess the influence of photoperiod on morph determination. This design is essential in comparing morph ratios of progeny reared under different treatments since it eliminates confounding influences due to intercross variation. In the split brood experiments, newly hatched individuals were counted daily and randomly divided between the two treatments. Individuals were added to a particular container over no more than a six day period. This was done to eliminate cannibalism of older nymphs on younger nymphs and for other reasons mentioned below.

Pair crosses were set up in two series (Fig. 1). In series I crosses, all parents had been reared under long-constant photoperiod, while in series II crosses, all parents had been reared under short-decreasing photoperiod. Broods of series I crosses were split between long-constant and short-decreasing photoperiod or were reared exclusively under long-constant photoperiod. All progeny of series II crosses were reared under a short-decreasing photoperiod. Thus, in series I crosses, both parents and at least one-half of their progeny were reared under long-constant photoperiod, while in series II crosses, both parents and progeny were reared under short-decreasing photoperiod. The parents of series II crosses were progeny of series I crosses which had emerged as adults over a six day period (13:15L to $12: 30 \mathrm{~L})$.

Except for cross B, all progeny were placed in the short-decreasing photoperiod treatment during a 10 day period when photoperiod was decreased from $16 \mathrm{~L}$ to $14: 45 \mathrm{~L}$. Since progeny of cross B hatched later than those from other crosses, their initial exposure to the decreasing photoperiod treatment began between 15 and 14 hours of light. 
TABLE 2. Results of Series I crosses of Limnoporus canaliculatus. Parents had been reared under a long-constant photoperiod.

\begin{tabular}{|c|c|c|c|c|c|}
\hline \multirow[b]{4}{*}{ Parental phenotype } & \multirow{4}{*}{$\begin{array}{l}\text { Cross } \\
\text { name }\end{array}$} & \multicolumn{4}{|c|}{ Photoperiod treatment } \\
\hline & & \multicolumn{2}{|c|}{ Long-constant } & \multicolumn{2}{|c|}{ Short-decreasing } \\
\hline & & \multicolumn{2}{|c|}{$\begin{array}{c}\text { Number (proportion) } \\
\text { of progeny }\end{array}$} & \multicolumn{2}{|c|}{$\begin{array}{c}\text { Number (proportion) } \\
\text { of progeny }\end{array}$} \\
\hline & & MAC* & APT & MAC & APT \\
\hline \multirow[t]{5}{*}{$\mathrm{MAC} \times \mathrm{MAC}$} & A & $14(.88)$ & 2 & $13(.93)$ & 1 \\
\hline & B & $26(.52)$ & 24 & $50(.93)$ & 4 \\
\hline & E & $8(.73)$ & 3 & $21(.78)$ & 6 \\
\hline & $\mathrm{D}$ & $24(.80)$ & 6 & \multicolumn{2}{|c|}{ No data } \\
\hline & $\mathrm{F}$ & $12(.38)$ & 20 & \multicolumn{2}{|c|}{ No data } \\
\hline \multirow[t]{6}{*}{$\mathrm{APT} \times \mathrm{APT}$} & I & $0(.00)$ & 21 & $5(.25)$ & 15 \\
\hline & $\mathrm{J}$ & $1(.02)$ & 42 & $4(.57)$ & 3 \\
\hline & $\mathrm{L}$ & $1(.07)$ & 14 & $3(.30)$ & 7 \\
\hline & $\mathrm{P}^{* *}$ & $6(.25)$ & 18 & $1(.08)$ & 11 \\
\hline & M & $4(.07)$ & 56 & \multicolumn{2}{|c|}{ No data } \\
\hline & $\mathrm{O}$ & $0(.00)$ & 29 & \multicolumn{2}{|c|}{ No data } \\
\hline $\mathrm{APT} \$ \times \mathrm{MAC}+$ & $\mathrm{G}^{\delta}$ & $15(.54)$ & 13 & \multicolumn{2}{|c|}{ No data } \\
\hline \multirow[t]{2}{*}{ MAC $\delta \times$ APT $q$} & $\mathrm{H}$ & $5(.05)$ & 87 & $16(.41)$ & 23 \\
\hline & Q & $3(.08)$ & 33 & $13(.34)$ & 25 \\
\hline
\end{tabular}

* MAC and APT morphs were scored according to the classification of Brinkhurst (1959), MAC = long-winged morph, APT = wingless morph. Survivorship from egg hatch to at least fifth instar for all crosses except "L" in long-constant photoperiod was greater than $30 \%$ (avg = $49 \%$, range $=31 \%-71 \%$ ). Survivorship of cross " $\mathrm{L}$ " in long-constant photoperiod was $23 \%$.

** Two MIC $\partial$ produced in short-decreasing photoperiod; not included in the analysis.

$\delta 1$ MIC $\delta$ produced; not included in the analysis.

As mentioned above, siblings were added to the same container over no more than a six day period. This design resulted in a temporal series of replicates from each mating pair which could be compared for differences in morph ratios. Temporal trends among replicates within a cross in either photoperiod would indicate influence of rank order of eggs or some correlate on morph determination. Differences in morph ratios among replicates in only short-decreasing photoperiod would indicate the influence of absolute daylength on morph determination.

In this study we wished to rear individuals on a homogeneous reproducible medium such as distilled water. However, since constituents in pond water (e.g., emerging insects used as food by gerrids) might affect morph determination, results obtained using distilled water might be artificial and not directly related to morph determination in natural populations.

Consequently, as a control, broods of several series I crosses reared under long-constant photoperiod were split between pond and distilled water. Pond water was collected at the same locality as individuals used in crossing experiments and was kept at $24.5 \pm 1.5^{\circ} \mathrm{C}$ for five weeks prior to use. This enabled us to ensure that the experiments were not contaminated with gerrids produced from field laid eggs. No L. canaliculatus hatched from field collected water.

TABLE 3. Results of Series II crosses of Limnoporus canaliculatus. Parents were $F_{1}$ progeny of Series I crosses reared under short-decreasing photoperiod. All progeny were reared under short-decreasing photoperiod.

\begin{tabular}{|c|c|c|c|}
\hline \multirow[b]{2}{*}{ Parental phenotype } & \multirow{2}{*}{$\begin{array}{l}\text { Cross } \\
\text { name }\end{array}$} & \multicolumn{2}{|c|}{$\begin{array}{c}\text { Number (proportion) } \\
\text { of progeny }\end{array}$} \\
\hline & & MAC* & APT \\
\hline \multirow[t]{2}{*}{$\mathrm{MAC} \times \mathrm{MAC}$} & 3 & $9(.43)$ & 12 \\
\hline & 14 & $5(.50)$ & 5 \\
\hline \multirow{2}{*}{$\mathrm{APT} \times \mathrm{APT}$} & 12 & $3(.21)$ & 11 \\
\hline & 20 & $9(.15)$ & 53 \\
\hline \multirow[t]{2}{*}{$\mathrm{APT} \delta \times \mathrm{MAC} q$} & 7 & $11(.55)$ & 9 \\
\hline & 8 & $8(.36)$ & 14 \\
\hline
\end{tabular}

* MAC and APT morphs were scored according to the classification of Brinkhurst (1959), MAC = long-winged morph, APT = wingless morph (see Materials and Methods) Survivorship from egg hatch to at least fifth instar ranged from $42 \%-61 \%(\mathrm{avg}=51 \%)$ for all crosses. 
TABLE 4. Photoperiod dependent association between sex and morph type in progeny of crosses of Limnoporus canaliculatus.

\begin{tabular}{|c|c|c|c|c|c|}
\hline \multirow[b]{3}{*}{ Parental phenotype } & \multirow{3}{*}{$\begin{array}{l}\text { Cross } \\
\text { name }\end{array}$} & \multicolumn{4}{|c|}{ Photoperiod treatment } \\
\hline & & \multicolumn{2}{|c|}{$\begin{array}{l}\text { Long-constant } \\
\text { Frequency of MAC } \\
\text { progeny }\end{array}$} & \multicolumn{2}{|c|}{$\begin{array}{l}\text { Short-decreasing } \\
\text { Frequency of MAC } \\
\text { progeny }\end{array}$} \\
\hline & & $8 \delta$ & 99 & $8 \delta$ & $९$ \\
\hline \multirow[t]{7}{*}{$\mathrm{MAC} \times \mathrm{MAC}$} & A & $.90(10)^{*}$ & $.67(3)$ & $1.00(4)$ & $1.00(6)$ \\
\hline & B & $.58(12)$ & $.27(11)$ & $.88(16)$ & $.94(16)$ \\
\hline & $\mathrm{E}$ & $.83(6)$ & $.60(5)$ & $.70(10)$ & $.75(12)$ \\
\hline & $\mathrm{D}$ & $.82(11)$ & $.92(13)$ & \multicolumn{2}{|c|}{ n.d. } \\
\hline & $\mathrm{F}$ & $.50(14)$ & $.21(14)$ & & \\
\hline & 3 & \multicolumn{2}{|c|}{ n.d. $* *$} & $.22(9)$ & $.58(12)$ \\
\hline & 14 & \multicolumn{2}{|c|}{ n.d. } & $.50(2)$ & $.67(6)$ \\
\hline $\mathrm{APT} \times \mathrm{APT}$ & I & $.00(6)$ & $.00(14)$ & $.25(12)$ & $.25(8)$ \\
\hline & $\mathrm{J}$ & $.09(11)$ & $.00(17)$ & $.67(3)$ & $.67(3)$ \\
\hline & $\mathrm{L}$ & $.13(8)$ & $.00(1)$ & $.00(4)$ & $.60(5)$ \\
\hline & $\mathrm{O}$ & $.13(8)$ & $.00(3)$ & \multicolumn{2}{|c|}{ n.d. } \\
\hline & $\mathrm{P}$ & $.17(6)$ & $.29(7)$ & $.20(5)$ & $.00(7)$ \\
\hline & 12 & \multirow{2}{*}{\multicolumn{2}{|c|}{$\begin{array}{l}\text { n.d. } \\
\text { n.d. }\end{array}$}} & $.17(6)$ & $.40(5)$ \\
\hline & 20 & & & $.14(28)$ & $.18(28)$ \\
\hline \multirow[t]{3}{*}{$\mathrm{APT} \delta \times \mathrm{MAC}+$} & $\mathrm{G}$ & $.55(11)$ & $.50(16)$ & & \\
\hline & 7 & \multirow{2}{*}{\multicolumn{2}{|c|}{$\begin{array}{l}\text { n.d. } \\
\text { n.d. }\end{array}$}} & $.38(8)$ & $.70(10)$ \\
\hline & 8 & & & $.30(10)$ & $.42(12)$ \\
\hline \multirow[t]{3}{*}{ MAC $\delta \times$ APT $?$} & $\mathrm{H}$ & $.08(39)$ & $.00(34)$ & $.37(27)$ & $.50(12)$ \\
\hline & $\mathrm{Q}$ & $.25(12)$ & $.00(17)$ & $.35(17)$ & $.29(17)$ \\
\hline & \multicolumn{3}{|c|}{$\chi_{(1)}^{2}=5.33 ; P<.05^{\delta}$} & \multicolumn{2}{|c|}{$\chi^{2}=5.33 ; P<.05^{\delta}$} \\
\hline
\end{tabular}

* Number in parentheses refers to the total number of adult progeny scored for morph type.

** n.d. = no data

${ }^{\delta}$ Results of two tailed sign test (ties ignored), $H_{0}$ frequency of MAC $\hat{\delta}=$ frequency of MAC $q$. For a particular cross, the number of progeny reported in this table does not necessarily correspond to that reported In Tables 2 and 3 . Tables 2 and 3 contained unsexed progeny which were scored as fifth instars as well as progeny scored as adults (see Materials and Methods).

The two common morphs were classified according to the method of Brinkhurst (1959). Adults whose wings extended past the beginning of the seventh abdominal tergite were classified as macropters (MAC) while wingless individuals were classified as apters (APT). Rare individuals with wing lengths not reaching the anterior end of the seventh abdominal tergite were classified as micropters (MIC). Fifth instar nymphs which died before molting to adults were classified as MAC or APT, depending upon the presence or absence of wing pads. Of hundreds of individuals observed in this and other studies, MAC adults always molt from fifth instars with wing pads while APT adults always molt from fifth instars with no wing pads. There is a slight uncertainty in scoring fifth instars because rare individuals may molt into micropters (MIC). However, since only three of the 858 adults scored in this study were MIC, the probability of misscoring a fifth instar was very low. Data for micropterous progeny are given in Table 2. Because of their low frequency, they are not dealt with further.

\section{RESULTS}

Results of series I crosses are given in Table 2. In each photoperiod treatment, the proportion of MAC progeny produced by each MAC $\times$ MAC cross was greater than the proportion produced by each APT $\times$ APT cross. In general, the frequency of MAC progeny of MAC $\hat{\delta} \times$ APT $q$ and APT $\hat{\sigma} \times$ MAC $q$ crosses ranged between the frequency produced by MAC $\times$ MAC and APT $\times$ APT crosses. Both MAC and APT progeny were produced in nearly all MAC $\times$ MAC and APT $\times$ APT crosses in both photoperiods. 
Table 5. Number (Proportion) of MAC and APT progeny produced in "early" and "late" replicates of individual crosses of L. canaliculatus in long-constant photoperiod. See Materials and Methods for additional details

\begin{tabular}{|c|c|c|c|c|}
\hline & & \multicolumn{2}{|c|}{ Number (proportion) of progeny } & \multirow{2}{*}{$\begin{array}{l}\text { Relative proportion of MAC } \\
\text { morphs in "late" versus "early" } \\
\text { replicates and results of } \chi^{2} \\
\text { homogeneity tests }\end{array}$} \\
\hline \multicolumn{2}{|c|}{ Parental phenotypes and cross designation } & MAC & APT & \\
\hline MAC $\times$ MAC-B & $\begin{array}{r}\text { Early (E) } \\
\text { Late (L) }\end{array}$ & $\begin{array}{r}2(.14) \\
22(.61)\end{array}$ & $\begin{array}{l}12 \\
14\end{array}$ & Higher, $P<.005$ \\
\hline MAC $\times$ MAC-D & $\begin{array}{l}\mathrm{E} \\
\mathrm{L}\end{array}$ & $\begin{array}{r}18(.78) \\
6(.86)\end{array}$ & $\begin{array}{l}5 \\
1\end{array}$ & Higher, n.s. \\
\hline $\mathrm{MAC} \times \mathrm{MAC}-\mathrm{F}$ & $\begin{array}{l}\mathrm{E} \\
\mathrm{L}\end{array}$ & $\begin{array}{l}7(.37) \\
5(.38)\end{array}$ & $\begin{array}{r}12 \\
8\end{array}$ & Higher, n.s. \\
\hline APT $\times$ MAC-G & $\begin{array}{l}\mathrm{E} \\
\mathrm{L}\end{array}$ & $\begin{array}{l}7(.37) \\
9(.60)\end{array}$ & $\begin{array}{r}12 \\
6\end{array}$ & Higher, n.s. \\
\hline MAC $\times$ APT-H & $\begin{array}{l}\mathrm{E} \\
\mathrm{L}\end{array}$ & $\begin{array}{l}3(.06) \\
2(.05)\end{array}$ & $\begin{array}{l}52 \\
35\end{array}$ & Lower, n.s. \\
\hline MAC $\times$ APT-Q & $\begin{array}{l}\mathrm{E} \\
\mathrm{L}\end{array}$ & $\begin{array}{l}3(.14) \\
0(.00)\end{array}$ & $\begin{array}{l}19 \\
14\end{array}$ & Lower, n.s. \\
\hline APT $\times$ APT $-\mathrm{J}$ & $\begin{array}{l}\mathrm{E} \\
\mathrm{L}\end{array}$ & $\begin{array}{l}0(.00) \\
1(.07)\end{array}$ & $\begin{array}{l}29 \\
13\end{array}$ & Higher, n.s. \\
\hline APT $\times$ APT $-L$ & $\begin{array}{l}\mathrm{E} \\
\mathrm{L}\end{array}$ & $\begin{array}{l}0(.00) \\
1(.14)\end{array}$ & $\begin{array}{l}8 \\
6\end{array}$ & Higher, n.s. \\
\hline
\end{tabular}

Results of series II crosses are given in Table 3. The same general pattern was observed in these crosses as in series I crosses: the frequency of MAC progeny produced by each MAC $\times$ MAC cross was greater than that produced by each APT $\times$ APT cross; both MAC and APT progeny were produced in each MAC $\times$ MAC and APT $\times$ APT cross.

In eight of nine comparisons of the progeny of the same cross reared under different photoperiods (split-brood crosses), the frequency of MAC progeny was significantly higher in the short-decreasing than in the longconstant photoperiod $(P<.05$, two-tailed sign test). Sex ratio did not differ from 1:1 in either photoperiod.

A significant association between sex and morph type, as well as a sex $\times$ morph $\times$ photoperiod interaction was observed (Table 4). Ignoring ties, 10 of 12 crosses (B, E, 3, 14, 7, $8, \mathrm{H}, \mathrm{L}, 12,20)$ produced a higher frequency of MAC $q$ than MAC $\delta$ progeny in short-decreasing photoperiod $(P<.05$, two-tailed sign test). Cross $P$, which was the only cross which produced a higher frequency of MAC than APT morphs in long-constant versus short-de- creasing photoperiod, also was the only cross which produced a higher frequency of MAC of than MAC $q 0$ in short-decreasing and MAC $q$ q than MAC $\widehat{\partial} \widehat{o}$ in long-constant photoperiod.

No significant difference in morph ratios was observed in any of the "split brood" experiments in which progeny were reared on distilled versus pond water, nor was any trend observed $\left(P>.1\right.$ for all $\chi^{2}$ homogeneity tests; average sample size per treatment was 27 , sample size ranged from 11 to 48).

A comparison among temporal replicates within a cross could be made for eight crosses whose progeny were reared in longconstant photoperiod (Table 5). In one cross (B), the frequency of winged progeny was significantly greater in the later replicate $\left(\chi^{2}{ }_{(1)}=\right.$ $8.43, P<.005$; see Table 5). Of the remaining seven crosses, five exhibited non-significant increases in the frequency of winged progeny in late versus early replicates. Although late replicates tended to have a higher frequency of winged morphs, the difference over all crosses was non-significant $(P>.1$, two-tailed sign test; Table 5). 
Similar comparisons were made among temporal replicates of crosses reared in shortdecreasing photoperiod (crosses B, E, H, Q, 7, $20)$. In no case was a significant difference observed, nor was any trend observed $(P>.1$ for all homogeneity tests; average sample size per replicate was 17 , sample size ranged from 527).

\section{DISCUSSION}

The development of an individual Limnoporus canaliculatus into a macropterous (MAC) or apterous (APT) adult is determined by a complex interaction between genetic and non-genetic components. In both series I and II crosses, each MAC $\times$ MAC cross produced a higher frequency of MAC offspring than each APT $\times$ APT cross reared under the same photoperiod (Tables 2 and 3). This demonstrates a strong genetic component in morph determination. Since both MAC and APT progeny were produced in both $\mathrm{MAC} \times \mathrm{MAC}$ and APT $\times$ APT crosses, the results are inconsistent with a single-locus, two-allele model and require more complex multilocus or multiallelic models. In this study, as in many others (reviewed by Harrison, 1980), photoperiod exhibited a strong influence on morph determination (Table 2). The higher frequency of winged progeny produced in the short-decreasing photoperiod may have resulted from 1) the lower absolute daylength or, 2) decrease in daylength experienced by developing nymphs. With respect to absolute daylength, the differences between the two treatments are consistent with seasonal changes in morph frequencies in natural populations of $L$. canaliculatus (Table 1). A higher frequency of MAC individuals was observed in fall versus summer samples from each of four populations of L. canaliculatus (Table 1). Since absolute daylength decreases after the summer solstice (June 22), adults emerging later in the season developed under lower absolute daylengths than adults emerging earlier in the season. Slight differences in absolute daylength appeared to have no influence on morph determination since "early" versus "late" replicates in the short-de- creasing photoperiod treatment exhibited no significant difference in morph ratios. However, more detailed studies are needed to adequately determine whether different genotypes exhibit differential threshold responses to absolute daylength or to decremental change in daylength.

Development of an individual $L$. canaliculatus into a MAC or APT adult is also sexinfluenced, and the influence of sex is photoperiod-dependent (Table 4). Associations between sex and morph type observed in shortdecreasing photoperiod are consistent with data obtained from natural populations of $L$. canaliculatus and other gerrid species. In the laboratory, under short-decreasing photoperiod, nearly all crosses of $L$. canaliculatus produced a higher frequency of MAC $O 9$ than

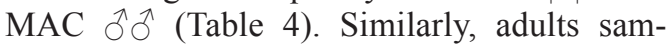
pled from 21 of 22 populations of this species from Maine to Florida in September-October, 1978-1979, exhibited a higher frequency of MAC 9 ㅇ than MAC $\widehat{\jmath} \widehat{\partial}(P<.005$, two-tailed sign test; Zera, unpubl.). Moreover, 7 of 8 fall and spring samples of $G$. lacustris exhibited a higher frequency of MAC 9 우 than MAC $\widehat{\partial} \widehat{\partial}$ (Fig. 1 of Anderson, 1973). Since overwintering occurs in the adult stage in gerrids, individuals sampled in the spring had developed under short-decreasing photoperiod, like adults sampled in the fall. Similar results for fall samples of Gerris lacustris were also obtained by Vepsäläinen (1974b; Tables 8-10, 21-22). The higher frequency of long-winged females produced in natural populations of L. canaliculatus suggests that dispersal rates may differ between the sexes.

A higher frequency of winged males than winged females was produced in the long-constant photoperiod treatment. This treatment is most similar to early summer (late June-July) with respect to absolute daylength. However, as mentioned previously, populations of $L$. canaliculatus are composed exclusively or almost exclusively of wingless morphs during this time (Table 1 ). Thus, this sex $\times$ morph association, if it occurs in natural populations of L. canaliculatus, is unlikely to be biologically important. 
In long-constant photoperiod, no overall difference in morph ratios was observed between "early" and "late" replicates (Table 5). However, the highly significant difference between replicates in one cross (B), coupled with the trend in the same direction in other crosses, suggests that such factors as rank order of eggs or maternal age may influence morph determination. Thus, these factors should be taken into account in future studies of wing polymorphism in gerrids. Influence of maternal age on morph determination has previously been documented in aphids (MacKay, 1977). In this study, we did not investigate the influence of other environmental variables which are likely to influence morph determination. For example, in many aphid species, temperature is known to strongly influence the development of an individual into a winged or wingless adult (Johnson, 1966; Lamb and White, 1966; Schaefers and Judge, 1971). Temperature also strongly influences the penetrance of the vestigal winged trait in Drosophila melanogaster (Stanley, 1931). Thus, morph determination in L. canaliculatus is likely to be even more complex than we have demonstrated.

Since there are no reliable genetic data for other wing-polymorphic gerrids, we do not know whether our results are typical for species of this family or are unique to L. canaliculatus. Genetic studies of wing polymorphism have been done in only a few other insects (summarized in Harrison, 1980). In the coleopteran Sitona hespidula, there is unambiguous evidence that wing polymorphism is controlled by a single locus (or supergene) with two alleles. Two other studies of wing polymorphism in coleopterans suggest a similar mode of inheritance. However, studies in other insect groups (e.g., Orthoptera and Hemiptera) are either inconclusive or demonstrate that wing polymorphism is more complex than a simple Mendelian trait (Harrison, 1980). Although the number of species examined is small, these data suggest that different taxonomic groups may exhibit different modes of inheritance of wing polymorphism.
An understanding of the mode of inheritance of wing polymorphism is a prerequisite for understanding the genetic basis of dispersal ability. Knowledge of the genetic basis of dispersal ability is, in turn, critically important in the development of realistic models of the evolution of dispersal. For example, Roff (1975) formulated a population model of dispersal in which the probability of dispersing was a function of genotype. In this model, the mode of inheritance of dispersal ability influenced both the stability of the dispersal polymorphism and the effect of environmental stability on the proportion of dispersers maintained in the population. These results were obtained for a wide range of dispersal and survival probabilities. Thus, realistic genetic mechanisms of dispersal ability must be incorporated if dispersal models are to accurately reflect processes occurring in natural populations.

In all single locus models of wing polymorphism, the allele for short wings (or winglessness) is dominant to the allele for long wings (Harrison, 1980). Since short-winged gerrids are unable to fly (Brinkhurst, 1958; Anderson, 1973), the only genotype capable of dispersal by flight is the homozygous recessive long-winged morph. If adult females are not inseminated prior to dispersal, the allele for short wings must be introduced into newly colonized habitats either through mutation or by gene flow dependent upon dispersal mechanisms other than flight (Harrison, 1980). Vepsäläinen (1978) recognized this problem and speculated that predispersal mating rather than mutation was a more probable way of introducing the allele for short wings into newly colonized habitats. However, he provided no evidence for insemination prior to dispersal and, in fact, stated that premigration mating is probably very rare in gerrids. If the mode of inheritance of wing polymorphism is shown to differ from the single-locus, two-allele model mentioned above, the introduction of the allele for winglessness into newly colonized habitats is no longer problematical. In this study, wingless progeny were produced in all crosses in which both parents were winged (Tables 2 and 3). 
Consequently, alleles for winglessness may be transmitted into newly colonized habitats via normal dispersal by flight, even if females are not inseminated. Important aspects of many hypotheses of the evolution of winglessness in gerrids are critically dependent upon the assumption that wing polymorphism is controlled by a single locus with two alleles. For example, Vepsäläinen's model (1978) of the evolution of dominance of short wings (or winglessness) is based on this assumption. Hypotheses which attempt to explain the maintenance of wing polymorphism in natural populations of gerrids are also dependent upon the assumption of a monogenic inheritance of wing polymorphism. For example, several investigators have evoked heterozygote superiority in attempting to explain wing polymorphism as a balanced polymorphism (Brinkhurst, 1959; Guthrie, 1959). Heterozygote superiority is a sufficient condition for the maintenance of polymorphism only for a single locus with two alleles (Crow and Kimura, 1970). The hypotheses mentioned above assume a particular mode of inheritance for which there are no reliable data. If the mode of inheritance for other gerrid species is similar to that of $L$. canaliculatus, the hypotheses are based on an erroneous assumption. Until more detailed information for both the genetic and environmental components of wing polymorphism become available, it will not be possible to formulate realistic models of the evolution of winglessness.

\section{SUMMARY}

Genetic and environmental factors influencing wing polymorphism in the waterstrider, Limnoporus canaliculatus, were analyzed by rearing progeny of single pair crosses in different photoperiods. There was a strong genetic component to morph determination, but results were inconsistent with a single-locus, two-allele mode of inheritance under either photoperiod. Photoperiod strongly influenced morph determination, with a higher proportion of long-winged morphs being produced in the short-decreasing photoperiod treatment. A pho- toperiod-dependent morph $\times$ sex association was also observed. In general, results were consistent with morph frequencies observed in natural populations of $L$. canaliculatus, as well as other gerrid species. These results are at variance with previous reports of a single-locus (or supergene), two-allele mode of inheritance of this trait in gerrids and have implications for currently developing models of the evolution of winglessness and dispersal.

\section{Acknowledgments}

We wish to acknowledge the cooperation of the staff of the Nissequogue River State Park especially Mr. Greg Mertz. We also thank the following persons who critically commented on an earlier draft of the manuscript: Drs. Diane M. Calabrese, Hugh Dingle, Richard G. Harrison, Kari Vepsäläinen and two anonymous reviewers. This study was supported by funds from the Department of Ecology and Evolution, State University of New York at Stony Brook. This is contribution number 430 from the Department of Ecology and Evolution, State University of New York at Stony Brook.

\section{Literature Cited}

Anderson, N. M. 1973. Seasonal polymorphism and developmental changes in organs of flight and reproduction in bivoltine pondskaters (Hem. Gerridae). Entomol. Scand. 4:1-20.

Brinkhurst, R. O. 1958. Alary polymorphism in the Gerroidea (Hemiptera-Heteroptera). Nature 182:1461-1462.

1959. Alary polymorphism in the Gerroidea (Hemiptera-Heteroptera). J. Anim. Ecol. 28: 211-230

Calabrese, D. M. 1979. Pterygomorphism in 10 Neartic species of Gerris. Amer. Midl. Natur. 101:61-68.

Crow, J. F., \& M. Kimura. 1970. An Introduction to Population Genetics Theory. Harper and Row, N.Y.

Denno, R. F., \& E. F. Grissell. 1979. The adaptiveness of wing-dimorphism in the salt marsh-in- 
habiting planthopper, Prokelisia marginata (Homoptera: Delphacidae). Ecology 60: 221-236.

Ekblom, T. 1941. Untersuchungen über den Flügeldimorphismus bei Gerris asper L. Not. Entomol. 21:49-64.

. 1949. Neue Untersuchungen über den Flügelpolymorphismus bei Gerris asper Fieb. Not. Entomol. 29:1-15.

Guthrie, D. M. 1959. Polymorphism in the surface water bugs (Hemipt.-Heteropt.:Gerroidea). J. Anim. Ecol. 28:141-152.

Harrison, R. G. 1980. Dispersal polymorphisms in insects. Ann. Rev. Ecol. Syst. 11:95-118.

Jarvinen, O., \& K. Vepsäläinen. 1976. Wing dimorphism as an adaptive strategy in waterstriders (Gerris). Hereditas 84:61-68.

Johnson, B. 1966. Wing polymorphism in aphids. IV. The effect of temperature and photoperiod. Entomol. Exp. App. 9:301-3 13.

Lamb, K. P., \& D. White. 1966. Effect of temperature, starvation and crowding on production of alate young by the cabbage aphid (Brevicoryne brassicae). Entomol. Exp. Appl. 9:179-184.

Mackay, P. A. 1977. Alate-production by an aphid: the "interval timer" concept and maternal age effects. J. Ins. Physiol. 23:889-893.

Poisson, R. 1924. Contribution a 1'étude des Hemipteres aquatiques. Bull. Biol. Fr. Belg. 58:49-305.

Roff, D. A. 1975. Population stability and the evolution of dispersal in a heterogeneous environment. Oecologia 19:217-237.
Schaefers, G. A., \& F. D. Judge. 1971. Effects of temperature, photoperiod, and host plant on alary polymorphism in the aphid, Chaetosiphon fragaefolii. J. Ins. Physiol. 17:365-379.

Stanley, W. F. 1931. The effect of temperature upon vestigal wing in Drosophila melanogaster, with temperature-effective periods. Physiol. Zool. 4:394-408.

Vepsäläinen, K. 1974a. Determination of winglength and diapause in waterstriders (Gerris Fabr., Heteroptera). Hereditas 77:163-175.

1974b. The life cycle and wing lengths of Finnish Gerris Fabr. species (Heteroptera, Gerridae). Acta. Zool. Finn. 141:1-73.

- 1978. Wing dimorphism and diapause in Gerris: determination and adaptive significance, p. 218-253. In H. Dingle (ed.), Evolution of Insect Migration and Diapause. Springer Verlag, N.Y.

Zera, A. J. 1981a. Genetic structure of two species of waterstriders (Gerridae: Hemiptera) with differing degrees of winglessness. Evolution, 35:218225 .

1981b. Extensive variation at the $\alpha$-glycerophosphate dehydrogenase locus in species of waterstriders (Gerridae: Hemiptera). Biochem. Genet. 19:797-812.

Corresponding Editor: G. B. Johnson 